\title{
Isolation and Characterization of cysK Mutants of Escherichia coli $\mathrm{K12}$
}

\author{
By A. L. FIMMEL AND R. E. LOUGHLIN \\ Department of Biochemistry, University of Sydney, \\ New South Wales 2006, Australia
}

(Received 26 April 1977)

\begin{abstract}
cys $K$ mutants, deficient in $O$-acetylserine sulphydrylase A [O-acetyl-L-serine acetate-lyase (adding hydrogen-sulphide); EC 4.2.99.8], were isolated as strains resistant to selenite or giving a black colour reaction on bismuth citrate indicator medium. All were resistant to the inhibitor I,2,4-triazole. Four independent mutants were found which possessed lowered levels of $O$-acetylserine sulphydrylase activity and also partially constitutive levels of NADPH-sulphite reductase [hydrogen-sulphide:NADP ${ }^{+}$oxidoreductase; EC I.8. I.2]. Strains containing both a $c y s E$ mutation and a $c y s K$ mutation lacked the constitutive levels of NADPH-sulphite reductase showing that these levels were due to the in vivo concentration of the inducer, $O$-acetylserine. The $c y s K$ locus was found to be $8 \mathrm{r} \%$ cotransducible with the $p t s I$ gene.
\end{abstract}

\section{INTRODUCTION}

In Escherichia coli KI2 and Salmonella typhimurium the cysteine biosynthetic pathway consists of two converging branches, the final step of which involves the reaction of $O$-acetyl-L-serine and sulphide to give L-cysteine (Jones-Mortimer, Wheldrake \& Pasternak, I968; Kredich \& Tomkins, I966). On the sulphur branch, sulphate is activated via adenosine $5^{\prime}$-phosphosulphate to form $3^{\prime}$-phosphoadenosine $5^{\prime}$-phosphosulphate which is reduced to sulphite and then to sulphide (Dreyfuss \& Monty, 1963; Pasternak et al., 1965). The enzyme NADPH-sulphite reductase [hydrogen-sulphide:NADP ${ }^{+}$oxidoreductase; EC r.8.I.2] catalyses the reduction of sulphite to sulphide (Siegel, Murphy \& Kamin, 1973; Siegel \& Davis, 1974; Siegel \& Kamin, 197I). Serine transacetylase [acetyl-CoA:L-serine $O$-acetyltransferase; EC 2.3.I.30], the enzyme of the carbon branch which converts serine and acetyl-coenzyme $\mathrm{A}$ into $O$-acetylserine, is coded for by the $c y s E$ gene in both organisms (Jones-Mortimer et al., 1968; Sanderson, 1972). In $S$. typhimurium the structural gene for one of the two final enzymes in the pathway, $O$-acetylserine sulphydrylase A [O-acetylL-serine acetate-lyase (adding hydrogen-sulphide); EC 4.2.99.8], has been designated cysK (Hulanicka, Kredich \& Treiman, 1974). Jones-Mortimer (1968) has shown that three conditions must be satisfied for the enzymes of the sulphur branch to be synthesized: the intracellular concentration of cysteine must be low to avoid repression; a wild-type allele of the $c y s B$ regulatory gene must be present in the cell; and the inducer, $O$-acetylserine, must also be present.

cys $K$ mutants of $S$. typhimurium, which have been isolated as strains resistant to the growth inhibitor I,2,4-triazole, possess low levels of $O$-acetylserine sulphydrylase activity while remaining prototrophic for cysteine (Hulanicka et al., 1974). The prototrophy of these strains is apparently due to the presence of a second $O$-acetylserine sulphydrylase which contributes only a small amount of the total activity of wild-type extracts (Becker \& 
Tomkins, I969; Hulanicka et al., I974). Kredich, Foote \& Hulanicka (1975) have shown that $O$-acetylserine sulphydrylase A catalyses a triazolylase reaction between $O$-acetylserine and I,2,4-triazole, giving I,2,4-triazole-I-alanine as a product. They have also shown that I,2,4-triazole lowers the activities of several of the enzymes necessary for sulphate reduction. Thus, inhibition of growth appears to be caused by cysteine starvation due to a decreased availability of the cysteine precursors, $O$-acetylserine and sulphide. Resistance to I,2,4triazole can arise from mutations leading to a preferential loss of triazolylase activity over sulphydrylase activity or from mutations which diminish both activities. They have proposed a model which suggests that there could be an accumulation of $O$-acetylserine in cys $K$ mutants of the second type. One can predict from this model that such cys $K$ mutants, when grown on sulphate, should have elevated levels of enzymes of the sulphur branch of the pathway and that the introduction of a mutation into the cys $E$ gene should abolish these elevated levels.

We report here the isolation and characterization of four cys $K$ mutants which possess elevated levels of NADPH-sulphite reductase. cysE cysK double mutants have been constructed which lack these elevated levels of NADPH-sulphite reductase. These observations lend further support to the model of Kredich et al. (I975).

\section{METHODS}

Chemicals. Glutathione, NADPH, Tris, I,2,4-triazole, DL-diaminopimelic acid (DAP), FAD, and 5-fluorouracil were obtained from Sigma. 5,5'-Dithiobis(2-nitrobenzoic acid) was obtained from Aldrich Chemical Co., Milwaukee, Wisconsin, U.S.A. O-Acetylserine was synthesized by the method of Sakami \& Toennies (1942). Ammonium bismuth citrate was purchased from Merck. Sodium selenite was from BDH.

Media. The nutrient medium used was L-broth (Lennox, 1955 ). The minimal medium used was medium E of Vogel \& Bonner (I956) modified by the replacement of $\mathrm{MgSO}_{4}$ by $\mathrm{MgCl}_{2}$ and supplemented with glucose $\left(0 \cdot 2 \%\right.$, w/v), amino acids $\left(40 \mu \mathrm{g} \mathrm{ml}^{-1}\right)$, thiamin $\left(4 \mu \mathrm{g} \mathrm{ml}^{-1}\right)$, DAP $\left(50 \mu \mathrm{g} \mathrm{ml}^{-1}\right)$ and other required growth factors. All solidified media contained $\mathrm{r} \cdot 5 \%(\mathrm{w} / \mathrm{v})$ agar. Bacteria for enzyme assays were grown in enriched liquid minimal medium which contained glucose $(0 \cdot 2 \%)$, a cysteine-free supplement of 19 amino acids (each at $30 \mu \mathrm{g} \mathrm{ml}^{-1}$ ) and the required vitamins. Cystine was added as described by Kredich (1971). Sulphur compounds were added as indicated. Glutathione and $O$-acetylserine were filter-sterilized. 5 -Fluorouracil was added at $2.5 \mu \mathrm{g} \mathrm{ml}^{-1}$.

Bismuth citrate-enriched minimal detection medium contained ammonium bismuth citrate $(0.15 \%, \mathrm{w} / \mathrm{v})$ and yeast extract $(0.02 \%$, w/v). Selenite minimal medium contained 0.25 mM-sodium selenite and I mM-Lmethionine. Triazole minimal medium contained $3 \mathrm{~mm}-\mathrm{I}, 2,4$-triazole. The sulphur source in these three

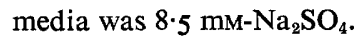

Bacterial strains. All the strains used were derived from E. coli $\mathrm{KI} 2$ and are listed in Table I.

Genetic techniques. Transductions with the generalized transducing phage PI were performed according to Miller (1972). Recombinants were screened by replica-plating and single colonies of the required type were selected and isolated.

Mutagenesis of strain PA309 by $N$-methyl- $N^{\prime}$-nitro- $N$-nitrosoguanidine (NTG) was carried out according to the procedure of Adelberg, Mandel \& Chen (1965); $10 \%$ of the cells survived a 20 min treatment with I00 $\mu \mathrm{g} \mathrm{NTG} \mathrm{ml}^{-1}$. The mutagenized cell suspension was distributed into 20 test tubes and incubated at $37^{\circ} \mathrm{C}$ overnight. About 100 cells from each culture were spread on to bismuth citrate indicator medium and selenite medium. Independent mutants, isolated as either black colonies on bismuth citrate agar or as red selenite-resistant colonies, were purified by restreaking on the same medium.

Mapping of the $c y s K$ locus was carried out by scoring the percentage cotransduction with the ptsI locus. The cotransduction frequency of the dapE marker with the ptsI gene was scored as a control in the same experiment. Positive selection for the cys $K$ marker is complicated by a high rate of spontaneous mutation and it was therefore used as the unselected marker in transductional crosses. Growth on mannitol or on glucose was used to select $p t s I^{+}$transductants and these were replica-plated on to minimal medium containing I,2,4-triazole to score the cotransduction of the $c y s K$ marker. The results for the two carbon sources were averaged. Since the $\operatorname{dap} E$ gene was also an unselected marker, the medium was supplemented with diaminopimelic acid.

Growth and disruption of bacteria. Cultures used for enzyme assays were grown as follows. An overnight L-broth culture ( $4 \mathrm{ml}$ ) was inoculated into $25 \mathrm{ml}$ enriched minimal medium and shaken overnight at $37^{\circ} \mathrm{C}$. A ro ml portion of this culture was inoculated into $200 \mathrm{ml}$ enriched minimal medium and shaken on a rotary 
Table I. Escherichia coli $\mathrm{KI} 2$ strains

\begin{tabular}{|c|c|c|c|}
\hline Strain & Sex & Description* & Source or derivation \\
\hline АT978 & HfrKLI 6 & thi-I, rel-r, dapEg, $\left(\lambda^{-}\right)$ & K. D. Brown \\
\hline FF8O28 & $\mathrm{F}^{-}$ & ptsI28, proC & W. Epstein \\
\hline JM7O & $\mathrm{F}^{-}$ & cysE, $m t l-2 \dagger$ & M. C. Jones-Mortimer \\
\hline PA309 & $\mathrm{F}^{-}$ & $m t l-2 \dagger$ & M. C. Jones-Mortimer \\
\hline $\mathrm{RC703}$ & $F^{-}$ & Wild-type & M. C. Jones-Mortimer \\
\hline RLlO3 & $\mathbf{F}^{-}$ & cys $E^{\dagger}$ & $\mathrm{RC} 703 \rightarrow \mathrm{JM} 70\left(\mathrm{Mtl}^{+}\right) \ddagger$ \\
\hline RLI 62 & $\mathbf{F}^{-}$ & cysK $4, m t l-2 \dagger$ & $\begin{array}{l}\text { NTG-induced mutant of } \\
\text { PA309 screened for black } \\
\text { colour reaction on bismuth } \\
\text { citrate medium }\end{array}$ \\
\hline RLI63 & $\mathbf{F}^{-}$ & cysK $7, m t l-2 \dagger$ & $\begin{array}{l}\text { NTG-induced mutant of } \\
\text { PA309 selected for resistance } \\
\text { to selenite }\end{array}$ \\
\hline RLI 64 & $\mathrm{~F}^{-}$ & cysK 8, mtl-2 $\dagger$ & As for RLI 63 \\
\hline RLI 65 & $\mathrm{~F}^{-}$ & cysKII, mtl-2 $\dagger$ & $\begin{array}{l}\text { Spontaneous selenite- } \\
\text { resistant mutant of PA309 }\end{array}$ \\
\hline RL166 & $\mathbf{F}^{-}$ & cysKII, mtl-2, upp, dapEg† & $\begin{array}{l}\text { RLI } 67 \times \text { RLI } 65 \text { (5-fluorouracil } \\
\text { resistance) } \ddagger\end{array}$ \\
\hline RLI67 & HfrKLI 6 & thi-I, rel-I, dapEg, upp, $\left(\lambda^{-}\right)$ & $\begin{array}{l}\text { This work; spontaneous } \\
5 \text {-fluorouracil-resistant mutant } \\
\text { of AT } 978\end{array}$ \\
\hline RLI7I & $\mathrm{F}^{-}$ & cys $K_{4}$, cys $E \dagger$ & RLIO3 $\rightarrow$ RLI62 $\left(\mathrm{Mtl}^{+}\right)$ \\
\hline RLI72 & $\mathrm{F}^{-}$ & cysK 7, cysE $\dagger$ & RLIO3 $\rightarrow$ RLI63 $\left(\mathrm{Mtl}^{+}\right)$ \\
\hline RLI73 & $\mathrm{F}^{-}$ & $\operatorname{cys} K \delta$, cys $E^{\dagger}$ & RLIO3 $\rightarrow$ RLI64 $\left(\mathrm{Mtl}^{+}\right)+$ \\
\hline RLI74 & $\mathrm{F}^{-}$ & cysKII, cysE $\dagger$ & RLI03 $\rightarrow$ RLI65 $\left(\mathrm{Mtl}^{+}\right) \dot{+}$ \\
\hline
\end{tabular}

* Mutant allele abbreviations according to Bachmann, Low \& Taylor (I976).

$\dagger$ Other markers: thr-I, leu-6, trp-I, his-I, argHI, thi-I, xyl-7, ara-13, gal-6, lacYI, tonA2, malAI, str-9, $\sup E,\left(\lambda^{-}\right)$.

$\ddagger$ Gene transfer: $\rightarrow$, PI transduction; $\times$, conjugation. The basis of selection is given in parentheses.

silaker at $37^{\circ} \mathrm{C}$. Growth was followed by measuring the turbidity of a I in Io dilution in $0.9 \%(\mathrm{w} / \mathrm{v}) \mathrm{NaCl}$ a $600 \mathrm{~nm}$ in a Unicam SP600 spectrophotometer. Cells were harvested in the late-exponential phase at $4{ }^{\circ} \mathrm{C}$, resuspended in $3 \mathrm{ml}$ cold $\mathrm{O}^{\mathrm{I}} \mathrm{M}$ M-potassium phosphate buffer $(\mathrm{pH} 7 \cdot 7)$ containing I mM-EDTA, and stored at $4{ }^{\circ} \mathrm{C}$ overnight. Cultures were checked for contamination by testing their phenotypic characteristics. Cells were disrupted using a Branson model B-I2 sonifier fitted with a microtip. Cell debris was removed by centrifuging at $28000 \mathrm{~g}$ for $40 \mathrm{~min}$ and the supernatants (crude extracts) were used for enzyme and protein assays. FAD was added to the extracts to a concentration of $5 \mu_{\mathrm{M}}$ in order to stabilize NADPH-sulphite reductase.

$N A D P H$-sulphite reductase assay. This activity was followed by measuring the initial rate of NADPH oxidation at $340 \mathrm{~nm}$ in a Cary spectrophotometer. Cuvettes contained (in $\mathrm{I} \cdot 0 \mathrm{ml}$ ): $200 \mu_{\mathrm{M}-\mathrm{NADPH}, 50}$ mM-potassium phosphate buffer ( $\mathrm{pH} 7 \cdot 7$ ), $600 \mu_{\mathrm{M}}-\mathrm{Na}_{2} \mathrm{SO}_{3}$, $100 \mu_{\mathrm{M}}$-EDTA (added in phosphate buffer), and $0.2 \mathrm{ml}$ crude extract. A control lacking sulphite was run for each assay. All extracts were assayed in duplicate and corrected for any activity present in the control.

$O$-Acetylserine sulphydrylase assay. The incubation mixture (in $\mathrm{I} \cdot 0 \mathrm{ml}$ in small stoppered tubes) had a final $\mathrm{pH}$ of 7.5 and contained: Io mM-Tris/HCl buffer ( $\mathrm{pH} 8 \cdot 0$ ), $60 \mu \mathrm{M}$-EDTA (added in Tris/HCl buffer), $20 \mathrm{mM}-\mathrm{HCl}, 20 \mathrm{mM}-\mathrm{Na}_{2} \mathrm{~S}, 30 \mathrm{~mm}-O$-acetylserine, and $0.1 \mathrm{ml}$ crude extract [diluted as required in $0.1 \mathrm{M}-$ phosphate buffer $(\mathrm{pH} 7 \cdot 7)$ containing I mM-EDTA]. The reaction was started by the addition of crude extract and the incubation was carried out for $30 \mathrm{~min}$ at $37^{\circ} \mathrm{C}$. The reaction was stopped by the addition of $0.4 \mathrm{ml} 7.5 \% \mathrm{HPO}_{3}$. One drop of octanol and approximately $15 \mathrm{mg} \mathrm{NaCl}$ were added, and nitrogen was bubbled through for Io min to remove the remaining sulphide. The solution was then filtered through $4.25 \mathrm{~cm}$ Whatman no. I filter paper, and $0.6 \mathrm{ml}$ filtrate was added to $2.0 \mathrm{ml} 0 . \mathrm{I} \mathrm{M}$-Tris, $\mathrm{I} \cdot 0 \mathrm{ml}$ water and $0.05 \mathrm{ml}$ Ellman's reagent (Ellman, 1959). The absorbance was read at 412 $\mathrm{nm}$ and enzyme activities were calculated assuming an extinction coefficient of $\epsilon_{412}=13600 \mathrm{M}^{-1} \mathrm{~cm}^{-1}$. All extracts were assayed in duplicate.

Protein determination. Protein was determined by the method of Lowry et al. (I95I). 


\section{RESULTS \\ Isolation of cysK mutants}

Mutants were isolated on indicator media as described in Methods and in Table I. Each of the mutants was prototrophic and gave black colonies on bismuth citrate agar (wild-type colonies appear white), red selenite-resistant colonies on selenite agar (growth of wild-type colonies is inhibited on this medium), and each was resistant to 3 mM-1,2,4-triazole.

\section{$O$-Acetylserine sulphydrylase activity of cysK strains}

The four cysK mutants RLI62, RLI63, RLI64 and RLI65 had lowered levels of $O$-acetylserine sulphydrylase activity; these were approximately $5 \%$ of that found in the parent strain PA309 (Table 2).

\section{$N A D P H$-sulphite reductase activity of cys $K$ strains}

In order to isolate cys $K$ mutants with both lowered triazolylase and sulphydrylase activity, the mutants isolated on the indicator media were screened for constitutive levels of NADPH-sulphite reductase. This was carried out on the basis that high concentrations of $O$-acetylserine would be expected to accumulate before the lowered sulphydrylase reaction, causing induction of the enzymes of the sulphur branch of the pathway. The results for four mutants (RLI62, RLI63, RLI64 and RLI65) which had partially constitutive levels of NADPH-sulphite reductase are shown in Table 2. Five out of 12 mutants isolated by these techniques possessed these characteristics. None out of I4 isolated as being directly resistant to I,2,4-triazole possessed NADPH-sulphite reductase levels significantly above that of the parent strain.

To demonstrate that the partially constitutive levels of NADPH-sulphite reductase were dependent on the $O$-acetylserine concentration in vivo, a cys $E$ mutation was introduced by transduction into the four constitutive mutants. Since the cys $E$ gene codes for serine transacetylase, the enzyme responsible for producing $O$-acetylserine, this effectively blocked the production of $O$-acetylserine in the four transductants (RLI7I, RLI72, RLI73 and RL 174). As shown in Table 2, the NADPH-sulphite reductase levels in these cys $K$ cysE strains were much lower than in their $c y s K c y s E^{+}$parents. Thus an elevated $O$-acetylserine concentration in vivo is responsible for the induction of NADPH-sulphite reductase in these mutants.

To check that the four cys $K$ cys $E$ transductants still possessed a mutant cys $K$ gene, they were transduced back to $c y s E^{+}$. This was necessary since $c y s E$ mutants require cysteine for growth, which overcomes the inhibition by r,2,4-triazole (Hulanicka, Klopotowski \& Smith, 1972). All the cysK cys $E^{+}$transductants were resistant to I,2,4-triazole, indicating that a defective cys $K$ gene was still present.

Of two of the constitutive mutants tested, strains RLI62 and RLI63, both were found to have NADPH-sulphite reductase levels which were repressible by cystine when grown on this sulphur source (Table 2).

\section{Mapping the cysK mutation}

We found that the cys $K$ gene was cotransducible with the ptsI gene. Strain FF8028 was transduced to ptsI $I^{+}$using PI grown on strain RLI66 as the donor. Of $446 p^{2 t s} I^{+}$colonies selected on glucose plates, $75 \%$ were resistant to 1,2,4-triazole (cysK) and $12 \%$ were dapE. Similarly, of $559 \mathrm{ptsI^{+ }}$ colonies selected on mannitol plates, $86 \%$ were cysK and $7 \%$ dapE. Thus the cysK and dapE loci were found to be $81 \%$ and $9 \%$ cotransducible respectively with the ptsI locus. The cys $K$ locus therefore maps at approximately $52 \mathrm{~min}$ on the E. coli linkage map (Bachmann, Low \& Taylor, 1976). 
Table 2. Specific activities of enzymes of the cysteine biosynthetic pathway in cysK mutants and their parent strains

Strains were grown with $8.5 \mathrm{~mm}$-sulphate or $0.4 \mathrm{~mm}$-glutathione (GSH) or $0.4 \mathrm{~mm}$-cystine as sulphur source. In some experiments, $2 \mathrm{~mm}-O$-acetylserine was added to the medium. Enzyme assays were carried out as described in Methods: $O$-acetylserine sulphydrylase activities are expressed as $\mu$ mol cysteine formed (mg protein $)^{-1} \mathrm{~h}^{-1}$, and NADPH-sulphite reductase activities as nmol NADPH oxidized (mg protein) ${ }^{-1} \mathrm{~min}^{-1}$.

Strain and

description

PA309 $\left(\right.$ cys $\left.K^{+}\right)$

PA309 $\left(\right.$ cys $\left.K^{+}\right)$

RLI62 (cysK)

RLI63 (cysK)

RLI64 (cysK)

RLI65 (cysK)

RLI62 (cysK)

RLI63 (cysK)

RLIO3 (cysK ${ }^{+}$cysE)

RLIO3 (cysK ${ }^{+}$cysE)

RLI7I (cysK cysE)

RLI72 (cysK cysE)

RLI73 (cysK cysE)

RLI74 (cysK cysE)

$\begin{array}{cc}\begin{array}{c}\text { Sulphur } \\ \text { source }\end{array} & \text { O-Acetylserine } \\ \mathrm{SO}_{4}{ }^{2-} & - \\ \mathrm{GSH}^{-} & + \\ \mathrm{SO}_{4}{ }^{2-} & - \\ \mathrm{SO}_{4}^{2-} & - \\ \mathrm{SO}_{4}^{2-} & - \\ \mathrm{SO}_{4}^{2-} & - \\ \text { Cystine } & - \\ \text { Cystine } & - \\ \text { GSH } & - \\ \text { GSH } & + \\ \text { GSH } & - \\ \text { GSH } & - \\ \text { GSH } & - \\ \text { GSH } & -\end{array}$

+ , Present; - , absent; ND, Not determined.
Enzyme specific activity

$\begin{array}{cc}\begin{array}{c}\text { O-Acetylserine } \\ \text { sulphydrylase }\end{array} & \begin{array}{c}\text { NADPH-sulphite } \\ \text { reductase }\end{array} \\ 41 \mathrm{I} \cdot 3 & 3.7 \\ \text { ND } & 38 \cdot 2 \\ 19 \cdot 0 & 16.8 \\ 33 \cdot 2 & 21 \cdot 8 \\ 23.9 & 11 \cdot 2 \\ \text { I6.4 } & 27 \cdot 2 \\ \text { ND } & <0.5 \\ \text { ND } & <0.5 \\ \text { ND } & 1 \cdot 3 \\ \text { ND } & 30.5 \\ \text { ND } & 4.4 \\ \text { ND } & 2.9 \\ \text { ND } & 3.6 \\ \text { ND } & 4.3\end{array}$

\section{DISCUSSION}

The isolation of cysK mutants of $E$. coli yielded some strains which possessed both lowered levels of $O$-acetylserine sulphydrylase activity and partially constitutive levels of NADPH-sulphite reductase. That this elevated NADPH-sulphite reductase level is dependent on a high $O$-acetylserine concentration in vivo was demonstrated by the observation that the introduction of a cys $E$ mutation into the pathway of $O$-acetylserine biosynthesis resulted in a significant lowering of the activity of NADPH-sulphite reductase in these mutants. Of the two strains assayed for repression of NADPH-sulphite reductase by cystine, this enzyme was found to be repressible in both. These observations support the hypothesis that in these cys $K$ mutants elevated levels of $O$-acetylserine accumulate before the lowered sulphydrylase reaction causing induction of NADPH-sulphite reductase. Concomitantly, if a decrease in the intracellular level of cysteine occurred as a result of the lowered sulphydrylase activity, conditions for derepression of NADPH-sulphite reductase would result.

Hulanicka et al. (1974) have reported that $S$. typhimurium cysK mutants grown on djenkolic acid as the sulphur source, possess the same derepressed levels as the wild-type strain for several enzymes of the sulphur branch of the pathway. The results reported in this paper show that NADPH-sulphite reductase levels in $E$. coli cys $K$ mutants are higher than in the parental strain when grown on sulphate which leads to partial repression of these enzymes in the wild type.

Only some cysK mutants have elevated NADPH-sulphite reductase levels. A possible explanation for the cys $K$ mutants which possess normal levels of NADPH-sulphite reductase is that there is a preferential loss of triazolylase activity over sulphydrylase activity, with the result that $O$-acetylserine does not accumulate but is metabolized to form cysteine.

Although the basis for the 1,2,4-triazole resistance of cys $K$ strains has been well documented (Kredich et al., I975), the basis for selenite resistance and the black colour reaction on bismuth citrate indicator medium is less well understood. Selenite, an analogue of sulphite, has been shown to inhibit the growth of $E$. coli (Scala \& Williams, I962), while 
$E$. coli grown on media containing sodium selenite will reduce the selenite to elemental selenium and give the culture a brick-red colour (Gerrard, Telford \& Williams, 1974). In $S$. typhimurium, a selenite-resistant mutant has been found to map at the locus for I,2,4-triazole resistance (Hulanicka et al., 1974).

The cys $K$ mutation in $S$. typhimurium (originally called the $\operatorname{trz} A$ mutation because it conferred resistance to I,2,4-triazole) maps at a point very close to the ptsI locus (Cordaro \& Roseman, I972). Our results indicate that it also maps very close to this gene in $E$. coli. The cotransduction frequency of $9 \%$ for the control experiment between the dapE and ptsI loci agrees with the value of $8 \%$ reported by Bukhari \& Taylor (I97I).

We wish to thank K.D. Brown and G. Zurawski for their helpful discussions relating to bacterial strain construction. We also thank M.C. Jones-Mortimer and W. Epstein for their generous donation of strains. This work was supported by a University of Sydney Research Grant. One of us (A.L.F.) is a recipient of a Commonwealth Postgraduate Research Studentship.

\section{REFERENCES}

Adelberg, E. A., Mandel, M. \& Chen, G. C. C. (I965). Optimal conditions for mutagenesis by $N$-methyl- $N^{\prime}$-nitro- $N$-nitrosoguanidine in Escherichia coli KI2. Biochemical and Biophysical Research Communications $18,788-795$.

BachmanN, B. J., Low, K. B. \& TAYloR, A. L. (1976). Recalibrated linkage map of Escherichia coli K-I 2. Bacteriological Reviews 40, I I6-I67

Becker, M. A. \& Tomkins, G. M. (I969). Pleiotropy in a cysteine-requiring mutant of Salmonella typhimurium resulting from altered proteinprotein interaction. Journal of Biological Chemistry 244, 6023-6030.

BukHaRI, A. I. \& TAYlor, A. L. (I97I). Genetic analysis of diaminopimelic acid- and lysinerequiring mutants of Escherichia coli. Journal of Bacteriology 105, 844-854.

Cordaro, J. C. \& Roseman, S. (1972). Deletion mapping of the genes coding for HPr and enzyme I of the phosphoenolpyruvate:sugar phosphotransferase system in Salmonella typhimurium. Journal of Bacteriology 112, 17-29.

Dreyfuss, J. \& MonTy, K. J. (I963). The biochemical characterization of cysteine-requiring mutants of Salmonella typhimurium. Journal of Biological Chemistry 238, I019-1024.

Ellman, G. L. (1959). Tissue sulphydryl groups. Archives of Biochemistry and Biophysics 82, 70-77.

Gerrard, T. L., Telford, J. N. \& Williams, H. H. (1974). Detection of selenium deposits in Escherichia coli by electron microscopy. Journal of Bacteriology II9, 1057-1060.

Hulanicka, D., Klopotowski, T. \& Smith, D. A. (1972). The effect of triazole on cysteine biosynthesis in Salmonella typhimurium. Journal of General Microbiology 72, 291-301.

Hulanicka, M. D., Kredich, N. M. \& Treiman, D. M. (1974). The structural gene for $O$-acetylserine sulphydrylase A in Salmonella typhimurium. Journal of Biological Chemistry 249, $867-872$.

Jones-Mortimer, M. C. (I968). Positive control of sulphate reduction in Escherichia coli. The nature of the pleiotropic cysteineless mutants of $E$. coli K12. Biochemical Journal 110, 597-602.
Jones-Mortimer, M. C., Wheldrake, J. F. \& PASTERnAK, C. A. (I968). The control of sulphate reduction in Escherichia coli by $O$-acetyl-L-serine. Biochemical Journal 107, 5I-53.

KREDICH, N. M. (I97I). Regulation of L-cysteine biosynthesis in Salmonella typhimurium. I. Effects of growth on varying sulphur sources and $O$-acetyl-L-serine on gene expression. Journal of Biological Chemistry 246, 3474-3484.

Kredich, N. M. \& Tomkins, G. M. (I966). The enzymic synthesis of L-cysteine in Escherichia coli and Salmonella typhimurium. Journal of Biological Chemistry 24r, 4955-4965.

Kredich, N. M., Foote, L. J. \& Hulanicka, M. D. (1975). Studies on the mechanism of inhibition of Salmonella typhimurium by 1,2,4-triazole. Journal of Biological Chemistry 250, 7324-733r.

LENNOX, E. S. (1955). Transduction of linked genetic characters of the host by bacteriophage Pr. Virology I, 190-206.

Lowry, O. H., Rosebrough, N. J., FARR, A. L. \& Randall, R. J. (I95I). Protein measurement with the Folin phenol reagent. Journal of Biological Chemistry 193, 265-275.

MilleR, J. H. (1972). Experiments in Molecular Genetics. Cold Spring Harbor, New York: Cold Spring Harbor Laboratory.

Pasternak, C. A., Ellis, R. J., Jones-Mortimer, M. C. \& CRICHTON, C. E. (I965). The control of sulphate reduction in bacteria. Biochemical Journal 96, 270-275.

SaKami, W. \& Toennies, G. (I942). The investigation of amino acid reactions by methods of non-aqueous titrimetry. II. Differential acetylation of hydroxy groups, and a method for the preparation of the $O$-acetyl derivatives of hydroxyamino acids. Journal of Biological Chemistry 144, 203-2I7.

SANDERson, K. E. (1972). Linkage map of Salmonella typhimurium, edition IV. Bacteriological Reviews 36, 558-586.

Scala, J. \& Williams, H. H. (I962). The enhancement of selenite toxicity by methionine in Escherichia coli. Archives of Biochemistry and Biophysics 99, 363-368. 
Siegel, L. M. \& Davis, P. S. (1974). Reduced nicotinamide adenine dinucleotide phosphatesulfite reductase of Enterobacteria. IV. The Escherichia coli hemoflavoprotein: subunit structure and dissociation into hemoprotein and flavoprotein components. Journal of Biological Chemistry 249, I 587-I 598.

Segel, L. M. \& Kamin, H. (I97I). TPNH-sulfite reductase (SiR) from $E$. coli and Salmonella typhimurium: subunit structure and gene assignment. Federation Proceedings 30, 1261.
Siegel, L. M., MurPhy, M. J. \& Kamin, H. (I973). Reduced nicotinamide adenine dinucleotide phosphate-sulfite reductase of Enterobacteria. I. The Escherichia coli hemoflavoprotein: molecular parameters and prosthetic groups. Journal of Biological Chemistry 248, $25 \mathrm{I}-264$.

VoGel, H. J. \& BonNeR, D. M. (1956). Acetylornithinase of Escherichia coli: partial purification and some properties. Journal of Biological Chemistry 218, 97-106. 